phys. stat. sol. (a) 121, 213 (1990)

Subject classification: $72.15 ; 75.60 ; \mathrm{S} 1.2$

Institute of Physics, Academia Sinica, Taipei ${ }^{1}$ ) (a),

National Taipei Institute of Technolog $\left.y^{2}\right)(b)$, and

Graduate Institute of Material Engineering, National Taiwan University, Taipei ${ }^{3}$ ) (c)

\title{
Electrical Resistivity, Magnetization, and Grain Boundary Precipitates in Ni-Sn Alloys
}

By

\author{
Y. D. Yao (a), Y. Y. Chen (a), S. J. Tzeng (b), and T. H. Chunang (c)
}

The variations of the electrical resistivity, the magnetization, and the grain boundary precipitates of a binary $\mathrm{Ni}-\mathrm{Sn}$ alloy system with Sn content up to 8 at $\%$ are investigated as functions of the annealing time at $773 \mathrm{~K}$. For samples homogenized at $1325 \mathrm{~K}$, clear grain boundaries are observed; the residual electrical resistivity is increased roughly by $2.81 \mu \Omega \mathrm{cm}$ per at \% of $\mathrm{Sn}$ and the Curie temperature is found to decrease roughly $32.5 \mathrm{~K}$ per at \% of Sn. However, for these aged samples both, grain boundary precipitates and variations of the electrical resistivity and the magnetization, are observed, the binary alloy with higher Sn content has the higher variation rate in the decrease of the electrical resistivity, the increase of the magnetization, and the growth of the grain boundary precipitates.

Für ein binäres Ni-Sn-Legierungssystem mit Sn-Gehalt bis zu $8 \mathrm{At} \%$ werden die Änderungen des elektrischen Widerstands, der Magnetisierung und der Korngrenzenpräzipitate als Funktionen der Temperungszeit bei $773 \mathrm{~K}$ untersucht. Für bei $1325 \mathrm{~K}$ homogenisierte Proben werden deutlich Korngrenzen beobachtet, der elektrische Restwiderstand nimmt ungefähr um $2.81 \mu \Omega \mathrm{cm}$ pro At $\% \mathrm{Sn}$ $\mathrm{zu}$, und die Curietemperatur nimmt etwa um $32,5 \mathrm{~K}$ pro At $\% \mathrm{Sn}$ ab. Jedoch werden für diese gealterten Proben sowohl Korngrenzenpräzipitate als auch Änderungen des elektrischen Widerstands und der Magnetisierung beobachtet, wobei die binäre Legierung mit höherem Sn-Gehalt die höhere Änderungsrate beim Abfall des elektrischen Widerstands, beim Anstieg der Magnetisierung und dem Wachstum der Korngrenzenpräzipitate aufweist.

\section{Introduction}

There has been considerable progress in the understanding of the morphology and growth kinetics of the grain boundary precipitates in binary alloy systems in the last few decades [1 to 3]. Little progress, however, has been made in the comprehension of the relationship between electrical resistivity, magnetization, and grain boundary precipitates of these binary alloy systems [4]. It is well known that electrical resistivity and magnetization are very sensitive to the composition change due to grain boundary precipitates, and hence these analyses are a very useful tool for identifying the variation of the grain boundary precipitates in many magnetic binary alloy systems. For the $\mathrm{Ni}-\mathrm{Sn}$ alloy system, the resistivity measurements have been predominantly confined to the very dilute $\mathrm{Ni}-\mathrm{Sn}$ alloys [5 to 7]. Therefore, we are motivated to study the electrical resistivity, the magnetization, and the relation of these properties to the grain boundary precipitates in the nickel-tin alloy system.

In this study, we report investigations of the variation of electrical resistivity, magnetization, and grain boundary precipitates of nickel-rich nickel-tin alloys containing Sn up to 8 at \% as functions of temperature between 4 and $800 \mathrm{~K}$ as well as the annealing time at $773 \mathrm{~K}$.

\footnotetext{
1) Taipei 11529, Taiwan.

2) Taipei 10643, Taiwan.

3) Taipei 10764, Taiwan.
} 


\section{Experimental Procedure}

The nickel-tin alloy samples containing $0,3.0$, and 8.0 at $\%$ of $\mathrm{Sn}$, were prepared by melting in an induction melter under positive pressure of argon and casting into $10 \mathrm{~mm}$ diameter molds. These ingots were homogenized at $1325 \mathrm{~K}$ for two weeks to remove any microscopic segregation. Samples for this study were cut from these ingots and were strain-relief annealed again in vacuum at $1325 \mathrm{~K}$ for $6 \mathrm{~h}$ and then water quenched. For heat treatment studies, samples in evacuated quartz tubes were annealed at $773 \mathrm{~K}$ for the electrical, magnetic, and microscopy studies. Typical sample dimensions were roughly $1 \times 2 \times 20 \mathrm{~mm}^{3}$ for the electrical resistivity study, $1 \times 2 \times 6 \mathrm{~mm}^{3}$ for the magnetization study, and $3 \times 9 \times 9 \mathrm{~mm}^{3}$ for the microscopy study.

The size of the grain boundary precipitates was determined from 50 measurements made in different regions of the sample. The data were averaged and multiplied by a factor of $\pi / 4$ to be consistent with the bulk averaging technique used by others previously [2]. The electrical resistivity of all samples was determined by using the conventional four-probe technique. The magnetization was measured by a vibrating sample magnetometer (VSM) above room temperature, and by both VSM and SQUID magnetometers below room temperature.

\section{Results and Discussion}

Fig. 1 shows the values of the electrical resistivity at $4 \mathrm{~K}, \varrho_{0}$, of our $\mathrm{Ni}-\mathrm{Sn}$ alloy samples which were homogenized at $1325 \mathrm{~K}$ as a function of Sn content. The increase in the electrical resistivity is about $2.81 \mu \Omega \mathrm{cm}$ per at \% of Sn. This plot confirms the expected good quality of these "homogenized" alloy samples. Fig. 2 shows the electrical resistivity of our "homogenized" $\mathrm{Ni}$-Sn samples containing $0,3.0$, and 8.0 at $\%$ of $\mathrm{Sn}$ between 4 and $800 \mathrm{~K}$. It is obvious that the $\varrho$ versus $T$ curves undergo an abrupt slope change which results from the ferromagnetic-paramagnetic phase transitions. The values of the Curie temperature $T_{\mathrm{C}}$ determined from $\mathrm{d} \varrho / \mathrm{d} T$ are 630,530 , and $370 \mathrm{~K}$ for pure $\mathrm{Ni}, \mathrm{Ni}-3$ at $\% \mathrm{Sn}$, and $\mathrm{Ni}-8$ at $\%$ $\mathrm{Sn}$, respectively. The Curie temperature decreases monotonically with a slope of roughly $32.5 \mathrm{~K}$ per at $\%$ of $\mathrm{Sn}$.

For both $\mathrm{Ni}-3$ at $\% \mathrm{Sn}$ and $\mathrm{Ni}-8$ at $\% \mathrm{Sn}$ samples, after thermal annealing at $773 \mathrm{~K}$, the electrical resistivity at $4 \mathrm{~K}$ decreases monotonically with annealing time. For example, Fig. 3 shows the variation of electrical resistivity of the $\mathrm{Ni}-3$ at \% $\mathrm{Sn}$ alloy system between 4 and $800 \mathrm{~K}$. Each curve is labelled by a number which indicates the annealing time (in days) at $773 \mathrm{~K}$. The resistivity is slowly decreased with increasing annealing time, and double knees are observed in the $\varrho-T$ curves for the two aged samples. From the $\mathrm{d} \varrho / \mathrm{d} T$ analysis between 500 and $650 \mathrm{~K}$ [4], we have observed double Curie temperatures in samples annealed at $773 \mathrm{~K}$. This suggests that besides the major phase of $\mathrm{Ni}_{0.97} \mathrm{Sn}_{0.03}$, there are some Ni-rich phases (with higher $T_{\mathrm{C}}$ ) which are precipitated during the annealing at $773 \mathrm{~K}$.

The drop of the electrical resistivity at $4 \mathrm{~K}$ as a function of annealing time at $773 \mathrm{~K}$ for both $\mathrm{Ni}-3$ at $\% \mathrm{Sn}$ and $\mathrm{Ni}-8$ at $\% \mathrm{Sn}$ is presented in Fig. 4 . The electrical resistivity at $4 \mathrm{~K}$ for the $\mathrm{Ni}-3$ at \% Sn sample decreases monotonically from $8.26 \mu \Omega \mathrm{cm}$ for the homogeneous sample to 6.80 and $6.02 \mu \Omega \mathrm{cm}$ for samples annealed at $773 \mathrm{~K}$ for 14 and 28 days, respectively. The slope of this decrease varies roughly from $0.10 \mu \Omega \mathrm{cm} /$ day at the beginning to $0.05 \mu \Omega \mathrm{cm} /$ day after 28 days of annealing. However, for the $\mathrm{Ni}-8 \mathrm{at} \% \mathrm{Sn}$ samples the electrical resistivity at $4 \mathrm{~K}$ decreases very fast after annealing, i. e., it decreases from $22.47 \mu \Omega \mathrm{cm}$ for the homogeneous sample to $6.95 \mu \Omega \mathrm{cm}$ for the sample annealed for 14 days 




Fig. 1

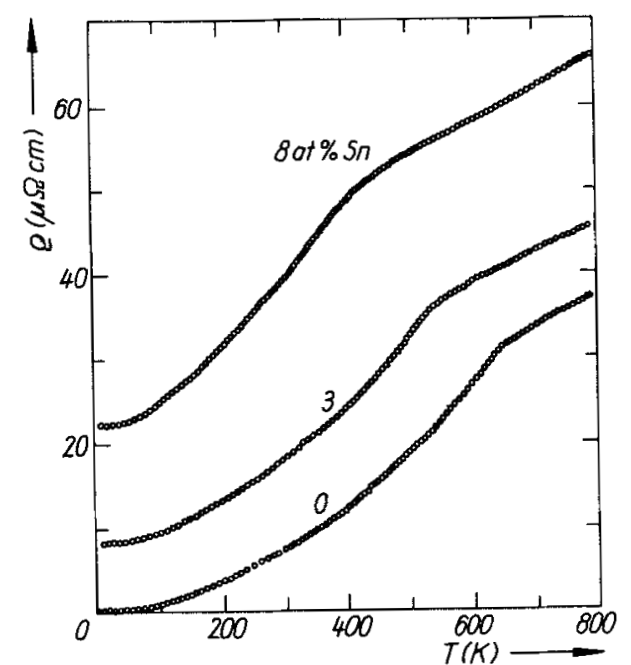

Fig. 2

Fig. 1. The electrical resistivity of the homogeneous $\mathrm{Ni}-\mathrm{Sn}$ alloys at $4 \mathrm{~K}$ as a function of the $\mathrm{Sn}$ concentration

Fig. 2. The electrical resistivity of the homogeneous $\mathrm{Ni}-\mathrm{Sn}$ alloys as a function of temperatures between 4 and $800 \mathrm{~K}$. The curves are labelled by the Sn concentration

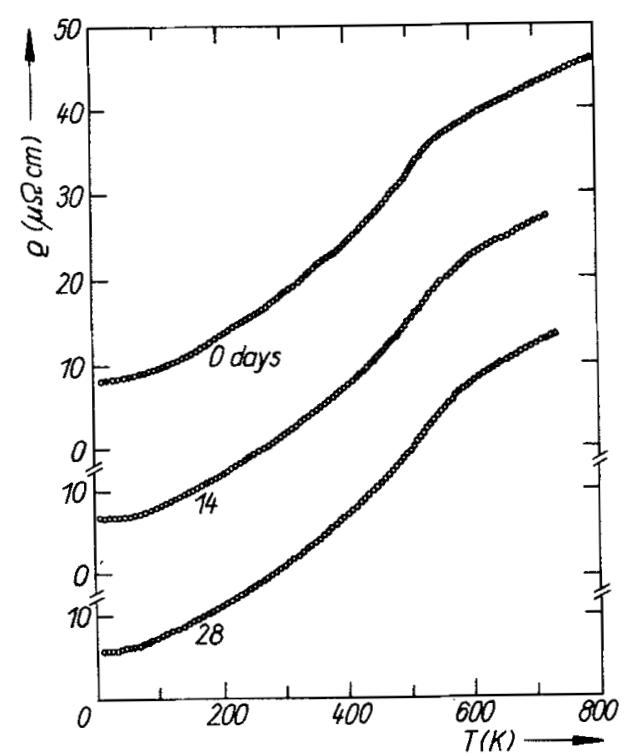

Fig. 3

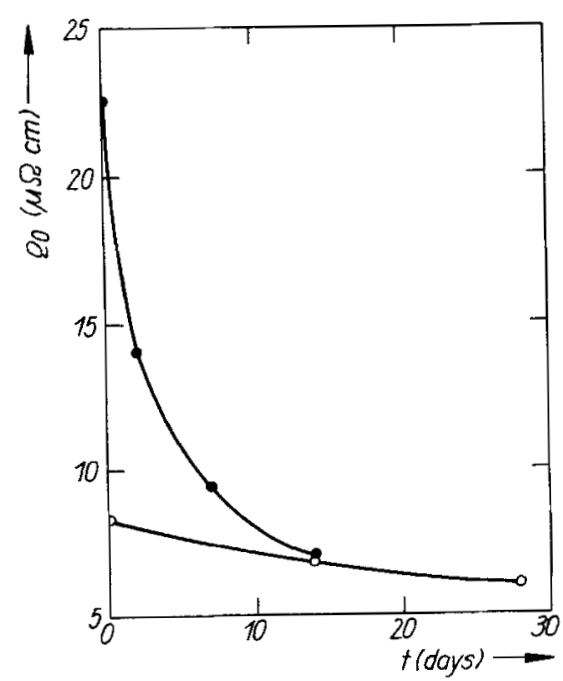

Fig. 4

Fig. 3. The electrical resistivity of the $\mathrm{Ni}_{0.97} \mathrm{Sn}_{0.03}$ sample as a function of temperature between 4 and $800 \mathrm{~K}$. The curves are labelled by the annealing days at $773 \mathrm{~K}$

Fig. 4. The variation of the electrical resistivity at $4 \mathrm{~K}$ as a function of annealing time at $773 \mathrm{~K}$ for both $\mathrm{Ni}-3$ at $\%$ Sn (O) and $\mathrm{Ni}-8$ at $\%$ Sn (๑) samples 


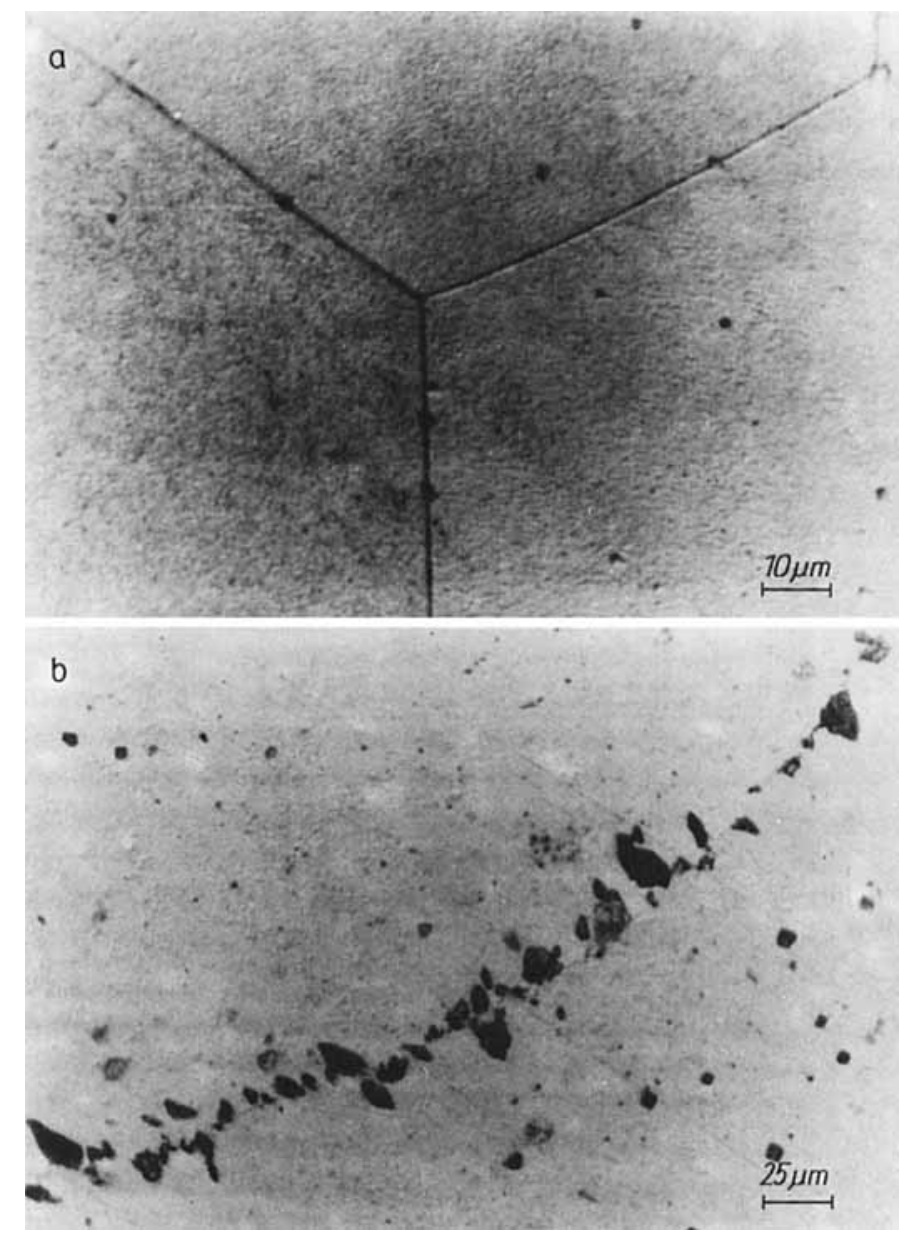

Fig. 5. a) Grain boundary of a homogeneous $\mathrm{Ni}-8$ at $\% \mathrm{Sn}$ sample. b) The grain boundary precipitates in a $\mathrm{Ni}-8$ at $\%$ Sn sample annealed at $773 \mathrm{~K}$ for 1 day

at $773 \mathrm{~K}$. The slope of this decrease is roughly $4.54 \mu \Omega \mathrm{cm} /$ day at the beginning, and it gradually slows down to roughly $0.26 \mu \Omega \mathrm{cm} /$ day after 14 days of annealing. This phenomenon suggests that the low-resistivity Ni-rich phase is easy to decompose from the binary solid solution at the beginning, and it may be gradually saturated after long-time annealing. Another interpretation is that this is a grain boundary phase size effect. As the grain boundary phase coarsens, the electrical resistivity would be expected to decrease, since there will be fewer scattering centres.

Clear grain boundaries were observed for samples homogenized at $1325 \mathrm{~K}$. However, for samples annealed at $773 \mathrm{~K}$ the cells of the grain boundary precipitates grew as a function of annealing time; as an example, Fig. 5 a shows the clear grain boundary of a "homogenized" $\mathrm{Ni}-8$ at \% Sn sample and Fig. $5 \mathrm{~b}$ presents the grain boundary precipitates of a $\mathrm{Ni}-8$ at $\%$ Sn sample which has been annealed at $773 \mathrm{~K}$ for one day. The average size of the cells of the grain boundary precipitates for this sample was found to be roughly $10 \mu \mathrm{m}$. The 


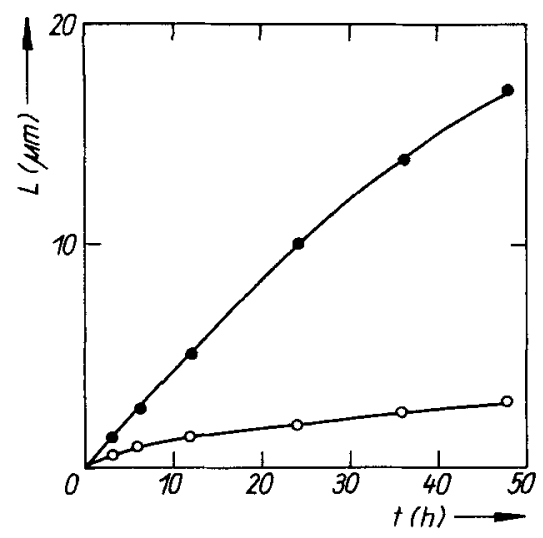

Fig. 6. The averaged size of the cells of the grain boundary precipitates as a function of annealing time at $773 \mathrm{~K}$ for $\mathrm{Ni}-3$ at \% Sn (O) and $\mathrm{Ni}-8$ at\% Sn (๑) samples

growth of the cells of the grain boundary precipitates is a function of both the Sn concentration and the annealing time at $773 \mathrm{~K}$. Fig. 6 shows the averaged size of the cells of the grain boundary precipitates $L$ as a function of annealing time $t$ at $773 \mathrm{~K}$ for $\mathrm{Ni}-3$ at $\% \mathrm{Sn}$ and $\mathrm{Ni}-8$ at $\% \mathrm{Sn}$ samples. The growth rate of grain boundary precipitates at the beginning is roughly 0.19 and $0.45 \mu \mathrm{m} / \mathrm{h}$ for $\mathrm{Ni}-3$ at $\% \mathrm{Sn}$ and $\mathrm{Ni}-8$ at\% $\mathrm{Sn}$ samples, respectively. It is gradually slowing down, and after two days of annealing, becomes 0.03 and $0.28 \mu \mathrm{m} / \mathrm{h}$ for $\mathrm{Ni}-3$ at $\% \mathrm{Sn}$ and $\mathrm{Ni}-8$ at $\% \mathrm{Sn}$ samples, respectively. Fig. 6 clearly tells us that in the case of the $\mathrm{Ni}-\mathrm{Sn}$ alloy system for a given annealing temperature, which is far below the annealing temperature for homogeneity, the alloy with higher soluteconcentration has the higher growth rate of grain boundary precipitates.

The magnetization at $0.8 \mathrm{~T}$ as a function of temperature between 5 and $800 \mathrm{~K}$ and annealing time at $773 \mathrm{~K}$ for both $\mathrm{Ni}-3$ at\% $\mathrm{Sn}$ and $\mathrm{Ni}-8$ at \% $\mathrm{Sn}$ samples are plotted in Fig. 7. Each curve is indicated by a number which reflects the annealing time (in days) at $773 \mathrm{~K}$. The upper three curves are experimental data of the Ni-3 at $\%$ Sn samples, the others are for the $\mathrm{Ni}-8$ at $\% \mathrm{Sn}$ samples. At least, two facts are evident from these plots. First, for a fixed concentration of the $\mathrm{Ni}-\mathrm{Sn}$ sample and at a special temperature below $T_{\mathrm{C}}$, the value of the magnetization always increases with aging time. Second, the area of the tail section for these annealed samples (the extra magnetization above $T_{\mathrm{C}}$ compared with the homogenized sample) increases with aging time. These tail sections of the magnetization go to zero roughly between 600 and $630 \mathrm{~K}$. Generally speaking, the magnetization of an inhomogeneous solid solution is given by a superposition of the magnetization for small regions of different solute concentrations. Therefore, our magnetization data also suggest the Ni-rich phases with higher $T_{C}$ values are precipitated. Following a similar analysis of the morphology and growth kinetics of the grain boundary precipitates as in [8], we conclude that both the nickel-rich phase and the $\mathrm{Ni}_{3} \mathrm{Sn}$ intermetallic compound are precipitated in the lamellar structure of the grain boundaries at all aging temperatures. One of the results of this precipitation and growth effect in the grain boundaries is the formation of solute-poor regions in the matrix which affect the decrease of the residual electrical resistivity and the appearance of the tail section of the superimposed magnetization curves shown in Fig. 7. In Fig. 8, the magnetization at $T=5 \mathrm{~K}$ and $H=0.8 \mathrm{~T}$ for samples annealed at $773 \mathrm{~K}$ is plotted as a function of annealing time. The value of the magnetization increases monotonically with increasing time from 47.1 e.m.u./g for a homogenized Ni-3 at \% Sn sample to 49.2 e.m.u./g for the same sample annealed at $773 \mathrm{~K}$ after 28 days. The slope of this curve is roughly 0.15 e.m.u./g per day. However, the magnetization of the $\mathrm{Ni}-8$ at $\%$ Sn sample increases much faster, i. e., it varies from 27.1 e.m.u./g for a homogenized sample to 33.1 e.m.u./g for the sample annealed at $773 \mathrm{~K}$ for 14 days. Its slope changes smoothly from 1.1 e.m.u./g per day at the beginning to 0.2 e.m.u./g per day after 14 days of annealing at $773 \mathrm{~K}$. 


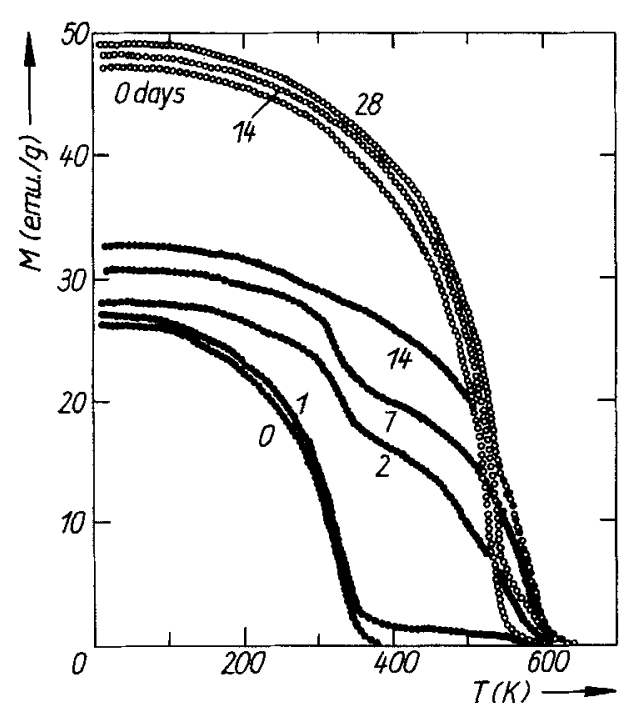

Fig. 7

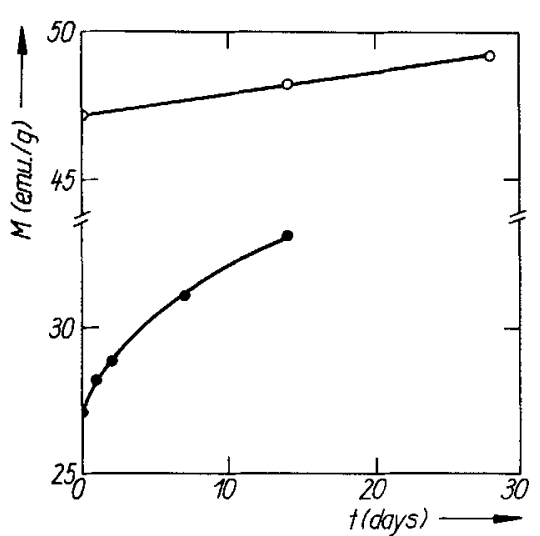

Fig. 8

Fig. 7. The magnetization at $H=0.8 \mathrm{~T}$ as a function of temperature between 5 and $800 \mathrm{~K}$ for $\mathrm{Ni}-3$ at $\%$ $\mathrm{Sn}(0)$ and $\mathrm{Ni}-8$ at \% $\mathrm{Sn}(\bullet)$ samples. The curves are labelled by the days of annealing at $773 \mathrm{~K}$

Fig. 8. The magnetization at $T=5 \mathrm{~K}$ and $H=0.8 \mathrm{~T}$ as a function of annealing time at $773 \mathrm{~K}$ for $\mathrm{Ni}-3$ at $\%$ Sn (O) and $\mathrm{Ni}-8$ at\% $\mathrm{Sn}(\bullet)$ samples

In conclusion, we have reported the results of an experimental study of the variations in the electrical resistivity, the magnetization, and the grain boundary precipitates of the binary $\mathrm{Ni}-\mathrm{Sn}$ alloy system containing $\mathrm{Sn}$ up to 8 at \% as functions of annealing time at $773 \mathrm{~K}$. For homogeneous samples, clear grain boundaries are observed, the residual electrical resistivity is increased roughly by $2.81 \mu \Omega \mathrm{cm}$ per at \% of $\mathrm{Sn}$, and the Curie temperature is found to derease roughly by $32.5 \mathrm{~K}$ per at \% of $\mathrm{Sn}$. However, for the binary Ni-Sn alloy system annealed at $773 \mathrm{~K}$, we have observed that both the electrical resistivity and magnetization vary as monotonic functions of the grain boundary precipitate size. Finally, the binary $\mathrm{Ni}-\mathrm{Sn}$ alloy system with higher Sn concentration shows the stronger decrease in the electrical resistivity, the increase of the magnetization, and the growth of grain boundary precipitates.

\section{Acknowledgement}

The authors are grateful to the National Science Council of the ROC for the financial support of this research work.

\section{References}

[1] D. B. Williams and E. P. Butler, Internat. Met. Rev. 26, 153 (1981).

[2] W. Gust, M. B. Hintz, R. Lucic, and B. Predel, Mater. Res. Soc. Symp. Proc. 21, 513 (1983).

[3] S. P. Gupta, Scripta metall. 20, 1323 (1986).

[4] Y. D. YAO, T. H. ChUANG, and C. K. LeE, IEEE Trans. Magnetics 25, 3958 (1989).

[5] J. W. F. DorleiJn and A. R. Miedema, J. Phys. F 5, 487 (1975).

[6] J. W. F. Dorleun, Philips Res. Rep. 31, 287 (1976).

[7] R. N. Ross, D. C. Price and Williams, J. Phys. F 8, 2367 (1978).

[8] T. H. Chuang, R. A. Fournelle, W. Gust, and B. Predel, Acta metall. 36, 775 (1988). 